\title{
BMJ Open Comparative analysis of developmental profile between normal and severe acute malnourished under-five children in Pakistan: a multicentre cross- sectional study
}

\author{
Javeria Saleem, ${ }^{1}$ Rubeena Zakar, ${ }^{1}$ Faisal Mushtaq, ${ }^{2}$ Gul Mehar Javaid Bukhari, ${ }^{3}$ \\ Florian Fischer (i) 4,5
}

To cite: Saleem J, Zakar R, Mushtaq F, et al. Comparative analysis of developmental profile between normal and severe acute malnourished under-five children in Pakistan: a multicentre crosssectional study. BMJ Open 2021;11:e048644. doi:10.1136/ bmjopen-2021-048644

- Prepublication history and additional supplemental material for this paper are available online. To view these files, please visit the journal online. (http://dx.doi.org/10.1136/ bmjopen-2021-048644).

Received 04 January 202 Accepted 04 August 2021
Check for updates

(C) Author(s) (or their employer(s)) 2021. Re-use permitted under CC BY-NC. No commercial re-use. See rights and permissions. Published by BMJ.

For numbered affiliations see end of article.

Correspondence to

Florian Fischer;

florian.fischer1@charite.de

\section{ABSTRACT}

Objectives This study aims to compare the developmental profile of severe acute malnourished (SAM) and normal under-five children and to find sociodemographic determinants accountable for their developmental disabilities.

Setting We conducted a multi-centre cross-sectional study in three basic health units and one rural health centre in Pakistan.

Participants 200 children (SAM and healthy) aged 6-59 months.

Primary and secondary measures We screened for nutritional status and clinical complications. Children underwent for developmental assessment by Denver Development Screening Tool II. A pretested structured questionnaire on sociodemographic characteristics and nutrition was used for collecting data about determinants of developmental delay.

Results We observed statistically significant differences in anthropometric measurements among SAM compared with normal nourished in weight, height, mid-upper arm circumference and weight-for-height z-scores. SAM serves as a significant risk factors $(p<0.001)$ for delayed personal or social development ( $69 \%$ vs $11 \%$; OR $(95 \% \mathrm{Cl})=18.01$ (8.45 to 38.37$)$ ), delayed fine motor development (39\% vs $8 \%$; OR $(95 \% \mathrm{Cl})=7.35$ (3.22 to 16.81$)$ ), delayed language development ( $32 \%$ vs $8 \%$; OR $(95 \% \mathrm{Cl})=5.41(2.35$ to $12.48)$ ), delayed gross motor development (34\% vs $10 \%$; OR $(95 \% \mathrm{Cl})=4.64(2.14$ to 10.05$))$ and delayed global development $(66 \%$ vs $20 \%$; OR $(95 \% \mathrm{Cl})=7.77$ (4.09 to 14.74)). Applying logistic regression, personal or social development $(p<0.001)$ and language development $(p<0.05)$, under-five siblings was a risk factor, while among gross motor development, mother's educational status $(p<0.05)$ was a significant risk factor for developmental delay.

Conclusions Our analysis indicates that children with malnutrition have a high frequency of developmental delays. Missing maternal education and a higher number of under-five siblings are also potential risk factors for developmental delay.

\section{Strengths and limitations of this study}

- Results are based on a multicentre cross-sectional analytical study.

- The study has been conducted in three basic health units and one rural health centre in the Dera Ghazi Khan District of Southern Punjab, Pakistan.

- The major limitation of this study is its crosssectional design, which does not allow for follow-up children for investigating factors that might affect the outcome.

\section{INTRODUCTION}

The word 'child development' designates progression of the child in all domains of human functioning, that is, social, cognitive, motor, hearing and speech. ${ }^{1}$ Global statistics from WHO showed that an estimated 45.4 million children under five, which are $6.7 \%$ of total under five, suffered from wasting, while 149.2 million children $(22 \%)$ suffered from stunting in 2021 . $^{2}$ Globally, children with severe malnutrition also contribute to more than 1 million under-five deaths annually. ${ }^{3}$ Regarding delayed developmental potential, United Nations International Children's Emergency Fund estimates of 2016 showed that more than $43 \%$ children under five are not up to the mark and as per World Bank statistics, around 250 million children in low-income and middle-income countries are having risk of delayed developmental potential. The reasons behind this could be poverty, poor nutrition as well as stunting (or less than standard height for age). ${ }^{45}$ The association between nutritional status and child development cannot be overemphasised, particularly in developing countries, as numerous studies have shown strong associations between the two. ${ }^{67}$ Many 
children under 5 years of age in developing countries are subject to multiple risks: poverty, poor health, malnutrition and the absence of a health promoting social environment adversely alter their development. ${ }^{6-8} \mathrm{~A}$ study from Jamaica showed that interventions of educating mothers in their primary care strategies regarding rearing of undernourished children provides significant results in the development of children with their hearing and speech, overall performance as well as coordination between hand and eyes. ${ }^{9}$

Severe acute malnutrition (SAM), as identified by the WHO, is a 'weight-for-height z-score (WHZ) $<-3 \mathrm{SD}$ of the median WHO growth standards or a mid-upper-arm circumference (MUAC) $<115 \mathrm{~mm}$, by visible severe wasting or presence of nutritional oedema'. It is the gravest form of under-nutrition, and, furthermore, categorised as complicated and uncomplicated SAM on the footing of the presence of medical complications. ${ }^{10}$ Malnutrition and developmental challenges are among the main health problems of childhood, specifically affecting developing countries. ${ }^{10}$ Malnutrition both affects physical growth, and it also results in delayed cognitive and motor growth of a child. ${ }^{11-13}$

However, malnutrition is not the only factor affecting children's physical and development growth. There are further promoting as well as risk factors that play their vital role in a child's upbringing and developmental potential. ${ }^{1}$ These risk factors are related to children's unconstructive sociocultural or caregiving environment, meagre stimulation, micronutrient deficiencies, lack of breastfeeding, housing, number of siblings, inappropriate child care, child health problems, chronic illness, family income, gender discrimination and school facilities. All of these may have a negative impact on attainment of a child's developmental potential. They are accountable for discrepancies in all developmental domains, such as personal social behaviour, motor skills, school performance, as well as cognitive and psychomotor development. $^{17}$

Pakistan is one of those developing countries where the population faces numerous issues: poverty plays a vital role as it results in poor health of children, and developmental disabilities along with malnutrition. ${ }^{14}$ Although the chronic malnutrition or stunting rate in children under-five has dropped slightly from $43.7 \%$ in 2011 to $40.2 \%$ in 2018 in Pakistan, the indicators of acute malnutrition or wasting have deteriorated from $15.1 \%$ in 2011 to $17.7 \%$ in $2018 .^{14}$

Despite the already available data on the nutritional profile of children under-five in Pakistan, there is still a scarcity of data which depicts how malnutrition correlates to the development of children. For that reason, the core objectives of this study are to compare the development of normal and SAM under-five children, and to find sociodemographic determinants accountable for developmental disabilities.

\section{METHODS}

\section{Study design and setting}

A multicentre cross-sectional analytical study was conducted in Outpatient Therapeutic Programme (OTP) Centres situated in three basic health units (BHUs) and one rural health centre (RHC) in the Dera Ghazi Khan District of Southern Punjab, Pakistan. This district has a high illiteracy rate and the majority of the population has a comparatively low socioeconomic status. It is also a disadvantaged district with a high prevalence of malnutrition and poverty, especially among children. ${ }^{14}$

Out of 16 OTP Centres in the Dera Ghazi Khan region, as per recommendations of the District Health Office, a total of four centres (three BHUs and one RHC) were selected. The recommendation implies that these centres were actively functioning in terms of staff members as well as availability of therapeutic food. Moreover, these selected centres were being used as screening centres for assessing nutritional status of the infants and children for timely recognition and also referring them in case of complications to other tertiary care facilities.

Participants with SAM were enrolled before receiving nutritional treatment from outpatient therapeutic programme centres of these health units. Healthy children were recruited from the immunisation centres and from polio campaign of the same health units who are coming for their regular immunisation in the same time period.

\section{Sample size calculation and eligibility criteria}

For sample size calculation, we used a formula for crosssectional studies taking early childhood disability prevalence (p) as $5.5 \%{ }^{15}$ and an error term (d) of 0.05 . According to this, the calculated sample size was $n=80$ in each group. Assuming non-responses, for the sake of having a large power and allowing for subgroup analyses, we aimed to include 100 children for each group. Therefore, 200 children (boys and girls) aged 6-59 months fulfilling the inclusion criteria were enrolled in the study after written consent of parents or caregivers (figure 1). The inclusion criteria for children with SAM was the presence of severe wasting as assessed by the protocols of WHO (weight-for-height $<-3$ SD and height-for-age $<-2$ $\mathrm{SD})$ without any complications of malnutrition. ${ }^{8}$ Children with physical defects, mentally retarded or clinically unfit were not included in the study. Children for the comparative group aged 6-59 months were enrolled if they had a normal nutritional status and were not suffering from any illness and disease.

\section{Baseline assessments}

A pretested questionnaire (online supplemental appendix) including items on sociodemographic characteristics and nutritional aspects was used to obtain the information. It included information on the age of the child, gender, income, household size and immunisation status of the child, parent's education and parent's profession, history of infections, weaning practices, 


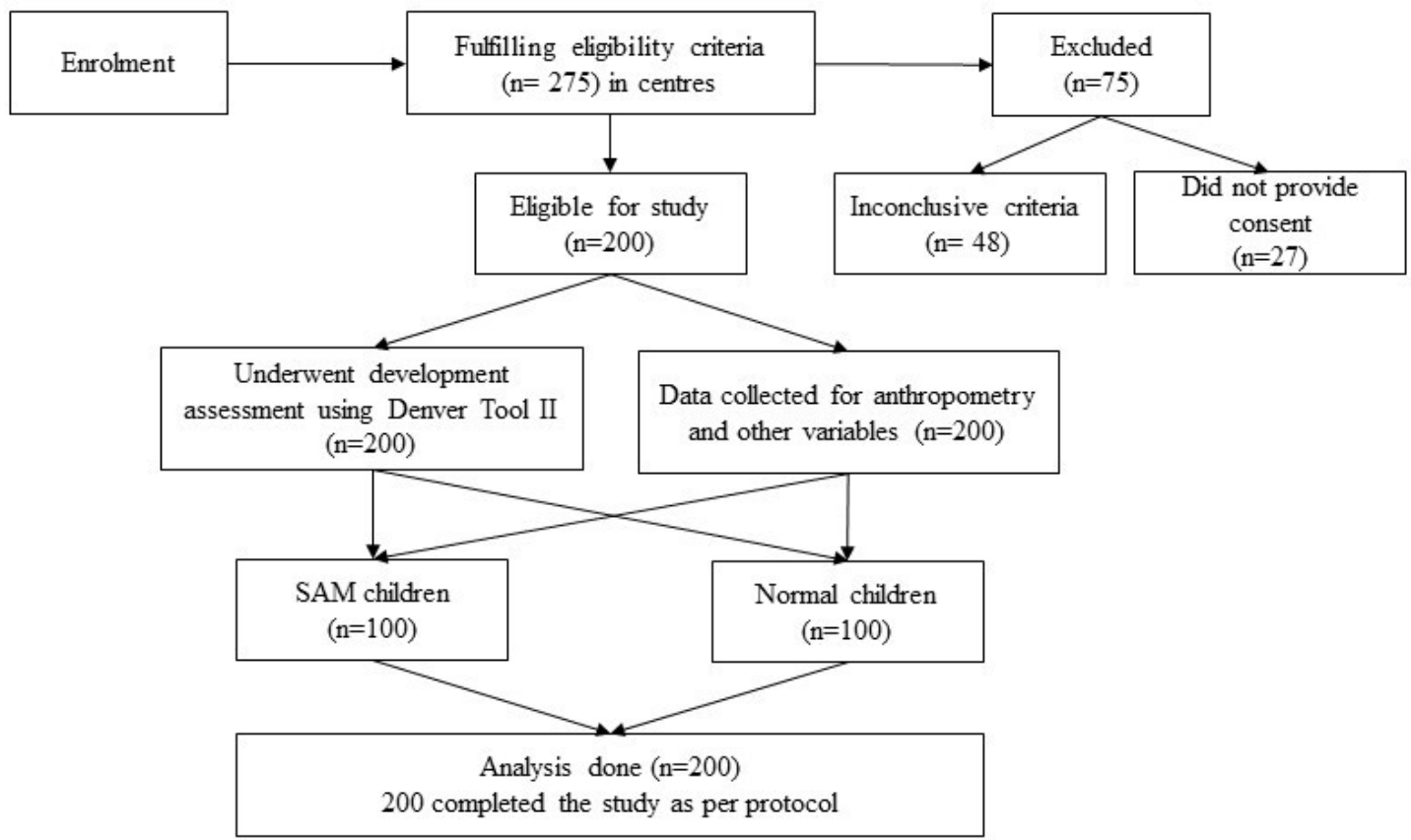

Figure 1 Flowchart. SAM, severe acute malnutrition.

breastfeeding and access to medical assistance. This information was obtained from mothers and caregivers at health units.

Children's gestational age was procured from the antenatal record in case of hospital delivery; and for home delivery, the information was based on a maternal report. For children who were $\leq 24$ months of age and born prematurely before 37 weeks of gestation, their age was adjusted by deducting the total weeks of missed gestation from the current age.

\section{Anthropometric assessments}

Anthropometric assessments were done by qualified nutritional supervisors who were specifically trained for these assessments. Weight was measured by using the UNISCALE nearest to the $10 \mathrm{~g}$ by weighing children with very light cloths or if necessary without cloths. For children who were unable to stand, their weight was taken with mother by holding the child and after that weight of the mother was excluded. Length of the child was assessed nearest to $0.1 \mathrm{~cm}$ with the help of a length measuring board ('SECA GmbH \& Co. KG, Hamburg, Germany'). Those children who could stand and were $>87 \mathrm{~cm}$ in height, their height was measured at a standing position without shoes. The quality of the measurements was accomplished using two times measurement procedure and taking average of the two figures. Weight-for-height z-scores were counted according to the WHO child growth standards with WHO ANTHRO, V.3.2.2.

\section{Developmental assessment}

Children after completing eligibility criteria underwent a development assessment with the help of a paediatrician by following the Denver Development Screening Tool II (DDST II). This development tool evaluates the child's ability until 6 years of age to perform a variety of different tasks and then compares them with a standardised populace of children of similar age. One hundred and twentyfive tasks are categorised into four domains: personal and social development, fine motor milestones, language skills and gross motor milestones. These four categories include tasks such as recognising people and also start care for their personal needs (personal and social develop$m e n t)$; coordination of eyes and hands, problem solving as well as tearing the papers apart (fine motor skills); understanding, hearing and saying words (language); walking, sitting, jumping and using of large muscles (gross motor skills). On the basis of these domains, final developmental status of children was concluded. ${ }^{16}$

\section{Statistical analyses}

The data collected were entered and analysed using SPSS V.23.0. The quantitative variables were expressed using means and SD, while categorical variables were expressed as frequencies and percentages. The $\chi^{2}$ test was applied to find associations of various factors among the two studied groups of children (SAM vs normal). The independent Student's t-test was applied to see the relationship between groups of quantitative variables. Logistic regression was applied to investigate potential risk factors for various development delays. These results are presented in terms of OR with $95 \%$ CI). For all analyses, a p-value $<0.05$ was considered as statistically significant.

\section{Patient and public involvement}

Neither patients nor public have been involved in the study.

\section{RESULTS}

About half $(48.5 \%)$ of the mothers of the study sample had no formal schooling. Of the 200 children, there were 
Table 1 Sociodemographic characteristics, anthropometric measurements and developmental status of severe acute malnourished and normal children $(n=200)$

\begin{tabular}{|c|c|c|}
\hline $\begin{array}{l}\text { Sociodemographic } \\
\text { characteristics }\end{array}$ & SAM $(n=100) \%$ & $\begin{array}{l}\text { Normal }(n=100) \\
\%\end{array}$ \\
\hline \multicolumn{3}{|l|}{ Gender } \\
\hline Male & 48 & 53 \\
\hline Female & 52 & 47 \\
\hline \multicolumn{3}{|l|}{ Mother's education } \\
\hline Illiterate & 64 & 33 \\
\hline Primary and above & 36 & 67 \\
\hline \multicolumn{3}{|l|}{ Under-five siblings } \\
\hline Two and less & 83 & 53 \\
\hline Three and more & 17 & 47 \\
\hline \multicolumn{3}{|l|}{ Exclusive breastfeeding } \\
\hline Yes & 17 & 47 \\
\hline No & 83 & 53 \\
\hline Age (months) mean $\pm S D$ & $16.09 \pm 11.16$ & $26.44 \pm 15.15$ \\
\hline Anthropometry & Mean (SD) & Mean (SD) \\
\hline Weight (kg) & $5.39(1.69)$ & $11.21(2.71)$ \\
\hline Height (cm) & $66.82(9.58)$ & $80.60(12.85)$ \\
\hline MUAC (cm) & $9.97(0.98)$ & $14.00(1.19)$ \\
\hline Weight-for-height z-score & $-4.07(1.25)$ & $0.40(1.27)$ \\
\hline Weight-for-age z-score & $-4.64(1.07)$ & $-0.58(2.79)$ \\
\hline Height-for-age z-score & $-3.94(1.41)$ & $-1.04(5.13)$ \\
\hline Developmental status & $\%$ & $\%$ \\
\hline $\begin{array}{l}\text { Delayed personal or social } \\
\text { development }\end{array}$ & 69 & 11 \\
\hline $\begin{array}{l}\text { Delayed fine motor } \\
\text { development }\end{array}$ & 39 & 8 \\
\hline $\begin{array}{l}\text { Delayed language } \\
\text { development }\end{array}$ & 32 & 8 \\
\hline $\begin{array}{l}\text { Delayed gross motor } \\
\text { development }\end{array}$ & 34 & 10 \\
\hline $\begin{array}{l}\text { Delayed global } \\
\text { development }\end{array}$ & 66 & 20 \\
\hline
\end{tabular}

MUAC, mid-upper arm circumference; SAM, severe acute malnourishment; SD, standard deviation.

$32 \%$ who had received exclusive breastfeeding. Gender was distributed almost equal (101 males and 99 females). Overall, the children had a mean (SD) age of 21.27 (14.25) months (table 1). Table 1 compares the characteristics between SAM and normal children. According to this table, the mean (SD) age among SAM children and normal children was 16.09 (11.16) months and 26.44 (15.15) months respectively. Furthermore, all sociodemographic variables (education of mothers, number of under-five siblings, exclusive breastfeeding), as well as anthropometric characteristics such as mean weight, height and MUAC among SAM was lower than in normal children. The developmental delay regarding personal or social development, fine motor development, language development, gross motor development and global development was higher in SAM children than in normal children.

The means for anthropometric measurements like weight, height, MUAC and weight-for-height z-scores were statistically significant when compared in SAM and normal children $(\mathrm{p}<0.001)$. SAM serves as a risk factor for delayed personal or social development, delayed fine motor development, delayed language development, delayed gross motor development and delayed global development as shown by OR. All of the above factors were also statistically significant $(\mathrm{p}<0.001)$ (table 2$)$.

The logistic regression regarding developmental delays and sociodemographic variables showed that among personal or social development $(\mathrm{p}<0.001)$ and language development $(\mathrm{p}<0.05)$, the number of under-five siblings was risk factor. Mother's education was significantly associated with a delay in gross motor development $(\mathrm{p}<0.05)$ and exclusive breastfeeding were significantly associated with personal or social development (table 3).

\section{DISCUSSION}

The results show that the frequency of developmental disabilities among SAM children aged 6-59 months is alarmingly high compared with their well-nourished counterparts in the study area of Punjab province in Pakistan. The SAM children enrolled in the study were performing poorly in all domains of developmental milestones, particularly in personal and social development. These results are comparable with previous studies as it was proved that severe malnutrition in children is one of the main reasons for alteration in brain development. This results in a reduction of brain size, dendritic arborisation and cell maturation, which subsequently leads to behavioural consequences producing social and behavioural disabilities that also affect child's adulthood. ${ }^{17}$

Children with SAM show compromised physical and cognitive development, which could depreciate their economic productivity later in life. ${ }^{11}$ During their first 2 years life, children are vulnerable due to higher body mass ratio. Rapid physical structure increases the need for nutritional requirements and also could face infection risks. ${ }^{18}$ Mortality numbers reduction due to SAM remains the priority for most and also survival rates are increasing with favourable outcomes. ${ }^{11}$ A systematic review consisting of 15 studies that included literature from Barbados and Mauritius large cohorts found significant results between SAM and various cognitive disabilities including problem solving, having short-term memory, working memory, intelligent quotient, cognitive processing along with academic skills. ${ }^{18-20}$

SAM children also showed a decreased developmental potential in language and motor milestones. It has been stated that children who suffered from SAM in the initial years of life showed developmental delay in all domains. A critical feature of malnutrition is the deficiency of different micronutrients-including iron, folate, vitamin A, and zinc — that are important for growth 
Table 2 Association of nutritional status among severe acute malnourished and normal children regarding anthropometric measurements and developmental status $(n=200)$

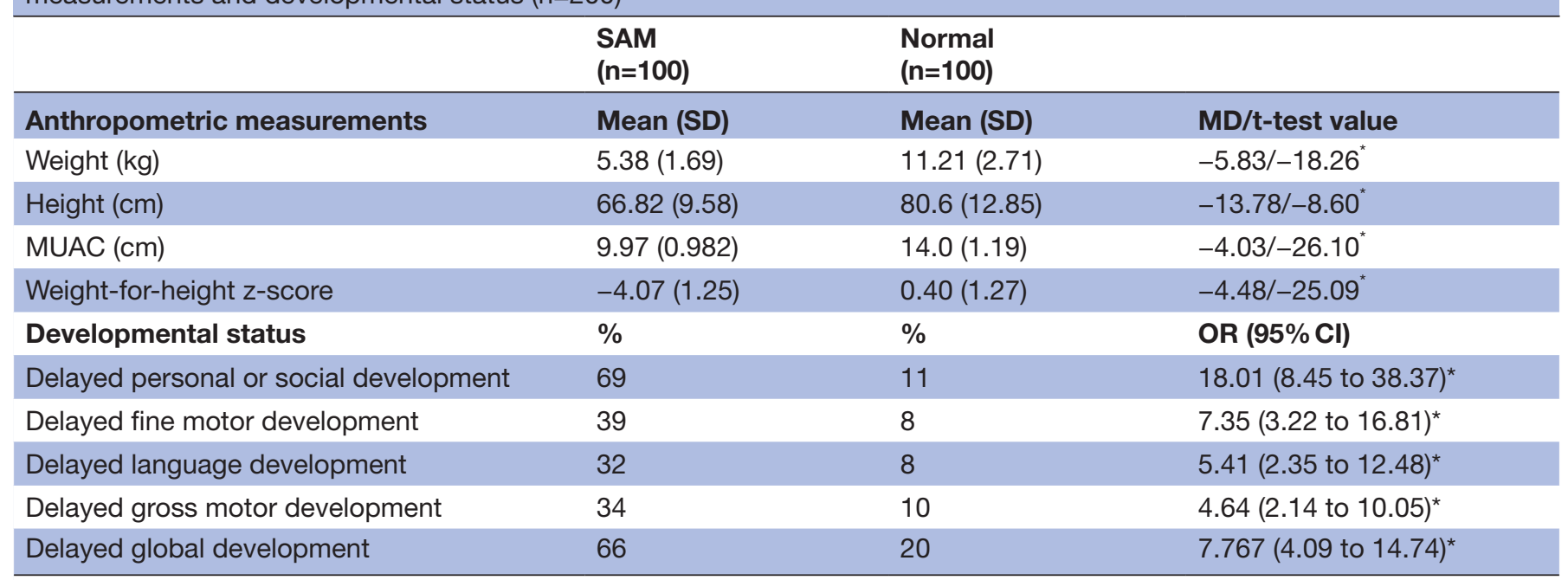

${ }^{*} p<0.001$.

Cl, confidence interval; MD, mean difference; MUAC, mid-upper arm circumference; OR, odds ratio; SAM, severe acute malnourishment; SD, standard deviation.

and development, particularly for cognitive functioning and brain development. ${ }^{721}$ A deficiency in calcium and vitamin $\mathrm{D}$ may result in delayed motor milestones. The developing brain of children is particularly susceptible to nutritional insults and nutritional deficiency even in the acute phase, cause impairment in normal functioning of the middle ear, affecting negatively the entire auditory system causing delay in speech and hearing domains. These children were then prone to face difficulties in verbal and written language. 223

Early childhood development is also determined by features of the child, the family and broader surroundings other than malnutrition. In our study, we have also tried to find out these features responsible for developmental delays in children. We found that mother's education showed significant associations with the developmental potential of children. There were more illiterate mothers among the SAM group. Illiteracy causes lots of problems in understanding the effect of malnutrition on the development of their children. These study findings are consistent with results of a study that showed a positive association between illiteracy of the mothers with the development of acute malnutrition. ${ }^{17}$

Another determinant of delayed development was the number of under-five siblings. Zhang $e t a l^{8}$ concluded in their study that developmental delays were associated with parenting, particularly meagre stimulation, caregiver sensitivity and emotional warm and responsive feeding for children. According to this, one might expect that an increased number of children limits the ability to pay proper care to each child which is required for their normal growth and development. ${ }^{8}$

We found that the frequency of children not receiving exclusive breastfeeding was much higher in the SAM group $(55 \%)$ compared with the normal group (6\%).
Findings from previous studies concluded that exclusive breastfeeding is one of the major factors preventing different forms of childhood malnutrition. ${ }^{67}$ Studies also correlate breastfeeding with high score achievement in cognitive tests and in motor and mental development because of breast milk being rich in long chain polyunsaturated fatty acids, and breast milk stimulates brain development, predominantly white matter growth. ${ }^{7}$

\section{Limitations}

Our study has some limitation as it is cross-sectional. We did not follow-up children for investigating factors that might affect the outcome. Observing the children's developmental and nutritional status in longitudinal studies would give a better insight of the dynamic nature of growth and development in children. Another limitation of our study is that factors like children's caregiving environment, meagre stimulation, micronutrient deficiencies and lack of breastfeeding were not assessed. However, the strength of our study is that we have used the Denver developmental screening test, ${ }^{16}$ which is a validated scale for developmental assessment of children. Furthermore, data collection has been conducted by well-trained medical staff by using established protocols.

\section{CONCLUSION}

In conclusion, our findings showed that SAM children have a high frequency of developmental disabilities in comparison with their well-nourished children in all domains. No education of mother and the higher number of under-five siblings were also significantly associated with delayed development in this vulnerable group. Moreover, screening in under-five children is not part of the regular 
Table 3 Logistic regression between sociodemographic characteristics and nutritional status of children ( $n=200)$

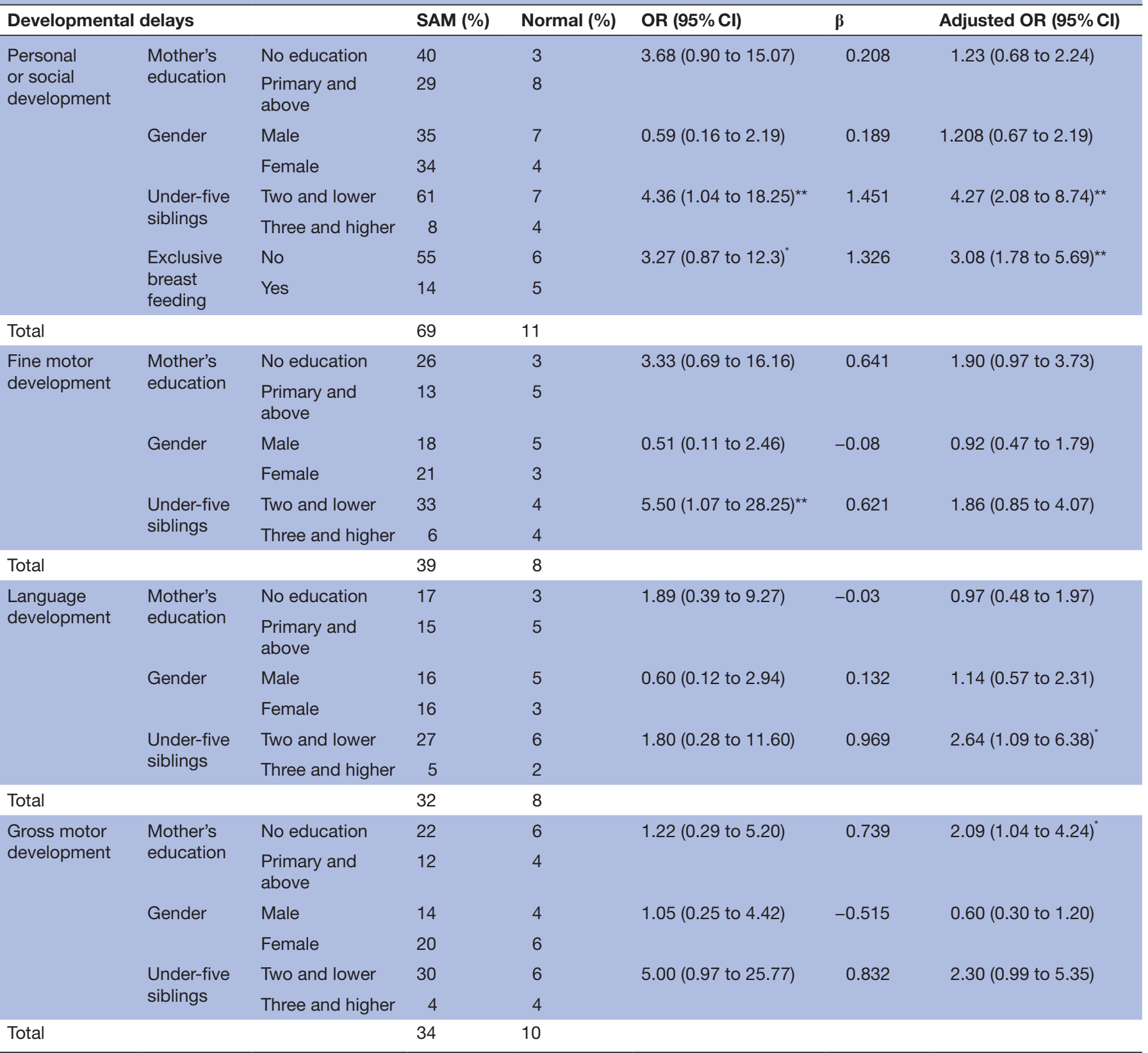

${ }^{*} \mathrm{p}<0.05 ;{ }^{* *} \mathrm{p}<0.001$.

$\mathrm{Cl}$, confidence interval; OR, odds ratio; SAM, severe acute malnourishment.

protocol in Pakistan. Therefore, this study will be helpful for policymakers to add this screening as a routine care.

\section{Author affiliations}

${ }^{1}$ Department of Public Health, Institute of Social and Cultural Studies, University of the Punjab, Lahore, Pakistan

${ }^{2}$ Institute of Public Health, Lahore, Pakistan

${ }^{3}$ Department of Community Medicine, Federal Medical and Dental College, Islamabad, Pakistan

${ }^{4}$ Institute of Public Health, Charité Universitätsmedizin Berlin, Berlin, Germany ${ }^{5}$ Institute of Gerontological Health Services and Nursing Research, University of Applied Sciences Ravensburg-Weingarten, Weingarten, Germany

Acknowledgements We acknowledge support from the German Research Foundation (DFG) and the Open Access Publication Fund of Charité Universitätsmedizin Berlin.
Contributors Conceptualisation: JS and RZ; formal analysis: JS; investigation: JS, RZ, FM and GMJB; supervision: FF; writing —original draft preparation: JS; writing — review and editing: RZ, FM, GMJB and FF. All authors have read and agreed to the published version of the manuscript.

Funding The authors have not declared a specific grant for this research from any funding agency in the public, commercial or not-for-profit sectors.

Competing interests None declared.

Patient consent for publication Written informed consent was obtained from caregivers or parents.

Ethics approval Ethical approval of the current study was obtained from the Ethical Review and Advanced Study Research Board of the University of Punjab, Pakistan (Ref.: 9/2352-ACAD), and the District Health Office of the Dera Ghazi Khan, Punjab, Pakistan.

Provenance and peer review Not commissioned; externally peer reviewed. 
Data availability statement Data are available upon reasonable request. Data is available upon reasonable request from the corresponding author.

Supplemental material This content has been supplied by the author(s). It has not been vetted by BMJ Publishing Group Limited (BMJ) and may not have been peer-reviewed. Any opinions or recommendations discussed are solely those of the author(s) and are not endorsed by BMJ. BMJ disclaims all liability and responsibility arising from any reliance placed on the content. Where the content includes any translated material, BMJ does not warrant the accuracy and reliability of the translations (including but not limited to local regulations, clinical guidelines, terminology, drug names and drug dosages), and is not responsible for any error and/or omissions arising from translation and adaptation or otherwise.

Open access This is an open access article distributed in accordance with the Creative Commons Attribution Non Commercial (CC BY-NC 4.0) license, which permits others to distribute, remix, adapt, build upon this work non-commercially, and license their derivative works on different terms, provided the original work is properly cited, appropriate credit is given, any changes made indicated, and the use is non-commercial. See: http://creativecommons.org/licenses/by-nc/4.0/.

ORCID iD

Florian Fischer http://orcid.org/0000-0002-4388-1245

\section{REFERENCES}

1 World Health Organization. Developmental difficulties in early childhood: prevention, early identification, assessment and intervention in low-and middle-income countries: a review. Geneva World Health Organization; 2012.

2 World Health Organization. Levels and trends in child malnutrition: UNICEF/WHO/The world bank group joint child malnutrition estimates: key findings of the 2021 edition. Geneva World Health Organization; 2021.

3 Ghimire U, Aryal BK, Gupta AK, et al. Severe acute malnutrition and its associated factors among children under-five years: a facilitybased cross-sectional study. BMC Pediatr 2020;20:1-9.

4 UNICEF. Developmental delay. Available: https://www.unicef.org/ press-releases/investing-early-childhood-development-essentialhelping-more-children-and [Accessed 05 Jul 2021].

5 World Bank. Early childhood development. Available: https://www. worldbank.org/en/topic/earlychildhooddevelopment [Accessed 05 Jul 2021].

6 Jimoh AO, Anyiam JO, Yakubu AM. Relationship between child development and nutritional status of under-five Nigerian children. South African Journal of Clinical Nutrition 2018;31:50-4.

7 Yakoob MY, Lo CW. Nutrition (micronutrients) in child growth and development: a systematic review on current evidence, recommendations and opportunities for further research. $J$ Dev Behav Pediatr 2017;38:665-79.

8 Zhang J, Guo S, Li Y, et al. Factors influencing developmental delay among young children in poor rural China: a latent variable approach. BMJ Open 2018;8:e021628.

9 Powell C, Baker-Henningham H, Walker S, et al. Feasibility of integrating early stimulation into primary care for undernourished Jamaican children: cluster randomised controlled trial. BMJ 2004;329:89-92.

10 World Bank. Severe acute malnutrition. Available: https://apps.who. int/nutrition/topics/severe_malnutrition/en/index.html [Accessed 05 Jul 2021]

11 Lelijveld N, Seal A, Wells JC, et al. Chronic disease outcomes after severe acute malnutrition in Malawian children (ChroSAM): a cohort study. Lancet Glob Health 2016;4:e654-62.

12 Olusanya BO, Davis AC, Wertlieb D, et al. Developmental disabilities among children younger than 5 years in 195 countries and territories, 1990-2016: a systematic analysis for the global burden of disease study 2016. Lancet Glob Health 2018;6:e1100-21.

13 Kinyoki DK, Osgood-Zimmerman AE, Pickering BV, et al. Mapping child growth failure across low- and middle-income countries. Nature 2020;577:231-4.

14 UNICEF. National nutrition survey 2018, Pakistan. Islamabad Government of Pakistan and UNICEF; 2018.

15 Ibrahim SH, Bhutta ZA. Prevalence of early childhood disability in a rural district of Sind, Pakistan. Dev Med Child Neurol 2013;55:357-63.

16 Frankenburg WK, Dodds J, Archer P, et al. The Denver II: a major revision and restandardization of the Denver developmental screening test. Pediatrics 1992;89:91-7.

17 Chertoff M. Protein malnutrition and brain development. Brain Disord Ther 2015;04:3.

18 Lelijveld N, Jalloh AA, Kampondeni SD, et al. Brain MRI and cognitive function seven years after surviving an episode of severe acute malnutrition in a cohort of Malawian children. Public Health Nutr 2019;22:1406-14.

19 Liu J, Raine A, Venables $\mathrm{PH}$, et al. Malnutrition at age 3 years and lower cognitive ability at age 11 years: independence from psychosocial adversity. Arch Pediatr Adolesc Med 2003;157:593-600.

20 Waber DP, Bryce CP, Girard JM, et al. Impaired IQ and academic skills in adults who experienced moderate to severe infantile malnutrition: a 40-year study. Nutr Neurosci 2014;17:58-64.

21 Chattopadhyay N, Saumitra M. Developmental outcome in children with malnutrition. Journal of Nepal Paediatric Society 2016;36:170-7.

22 Hill EL. Non-Specific nature of specific language impairment: a review of the literature with regard to concomitant motor impairments. Int J Lang Commun Disord 2001;36:149-71.

23 Saleem J, Zakar R, Zakar MZ, et al. High-Dose vitamin D3 in the treatment of severe acute malnutrition: a multicenter double-blind randomized controlled trial. Am J Clin Nutr 2018;107:725-33. 